\title{
Bombini, Gustavo
}

Resumen:

Frente a ciertas posiciones apocalípticas provenientes del ámbito escolar que vaticinan el ocaso de la lectura del libro impreso frente a la presencia de la cultura digital, el concepto de multimodalidad (Jewitt, 2005) y la apuesta a una construcción didáctica en el campo de la lectura y la escritura desarrollada a partir de ese concepto, proponen horizontes productivos en el territorio del aula y de la biblioteca escolar.

Palabras clave: Lectura - escritura multimodalidad - didáctica.

\section{${ }^{*}$ ) Profesor, Licenciado y Doctor en} Letras por la Universidad de Buenos Aires. Actualmente es profesor de la UBA y de la Universidad Nacional de

Juvenil y Director del Profesorado Universitario en Letras. Dicta habitualmente conferencias, cursos y seminarios en universidades nacionales y del extranjero. Ha dirigido investigaciones y publicado trabajos sobre Didáctica de la Lengua y la Literatura, políticas y prácticas de lectura, entre otras temáticas. Ha sido Coordinador General del Postítulo de Literatura Infantil del Gobierno de la Ciudad de Buenos Aires y Coordinador del Plan Nacional de Lectura y de la Coordinación de Materiales Educativos del Ministerio de Educación de la Nación.

Introducción

En un artículo pionero publicado en 1990 la investigadora Mabel Piccini indaga acerca de la incidencia que tienen las culturas electrónicas en la formación de niños y jóvenes de los sectores más pobres de la sociedad mexicana. Tratándose de un texto publicado al inicio de la última década del siglo pasado la referencia a lo que la autora llama "culturas electrónicas" son la radio y la televisión y restringido en su consideración a la experiencia cultural de niños y jóvenes, es por fin la televisión el objeto de consumo al que mayormente se hace referencia en el artículo en cuestión.

Pero lo que permite calificar a este artículo de "pionero" no es el hecho de que aborde la incidencia de la televisión en la formación cultural de niños y jóvenes sino que estas consideraciones se hagan en el marco de un proyecto de investigación que, en principio, tiene como recorte de corpus un programa de política pública de lectura de la Secretaría de Educación Pública mexicana, denominado “Libros del Rincón”. 
Se trata de un programa que tuvo su primera etapa, con una más nítida identidad, entre los años 1986 y 1989 que editaba (en convenio con editoriales privadas nacionales y extranjeras), imprimía y distribuía libros de literatura infantil y otros para bibliotecas escolares y las aulas del sistema educativo mexicano. En ese contexto, Piccini se propone poner en tensión la experiencia letrada tradicional que propicia la escuela y que es reforzada desde este programa de libros para aulas y bibliotecas con la experiencia de exposición y consumo de televisión en el contexto de los hogares. Piccini no se propone ponderar una cultura por sobre la otra sino que asume una posición que busca considerar ambas culturas, la tradicional y la "nueva", como parte de una hipótesis que recorre el artículo y a la que nosotros buscamos adherir en este trabajo que es el hecho de no oponer la cultura letrada y libresca a la cultura electrónica sino de observar los modos en que los sujetos se ponen en relación con ellas y avanzar en cierto conocimiento acerca de la distribución más o menos inequitativa en que ambas culturas se presentan como disponibles según algún criterio de segmentación social. De este modo, afirma Piccini“son, pues, los sectores más marginados los que se rinden a una exhaustiva exposición y a las gratificaciones inmediatas de los medios audiovisuales" (Piccini, 1993, p. 260).

Teniendo en cuenta estas consideraciones, en este artículo nos proponemos reflexionar a partir del concepto de multimodalidad (Jewitt, 2005) y la apuesta a una construcción didáctica en el campo de la lectura y la escritura desarrollada a partir de ese concepto, proponen horizontes productivos en el territorio del aula y de la biblioteca escolar.

La lectura y la escritura en la escuela frente a los desafíos de lo digital

Veinticinco años después de la indagación de Piccini (1993), podríamos relativizar sus posiciones a la luz de las consideraciones sobre el lector/espectador que realiza Michel de Certeau (1980) cuando se refiere a la actividad de la lectura como una cacería furtiva donde lectores y espectadores se definen como sujetos activos que incluso pueden asumir posiciones críticas, distanciadas e irónicas respecto de los contenidos que consumen.

Veinticinco años después hablar de culturas electrónicas supone centrarse en la experiencia de la cultura digital a la luz de todas las complejidades que la atraviesan en términos de accesibilidad a la conectividad, a la variedad de los dispositivos disponibles, a las habilidades técnicas para su uso y a las apropiaciones culturalmente significativas. Y en línea con el trabajo citado, indagar sobre las relaciones complejas entre cultura letrada y culturas electrónicas en el contexto escolar.

Esta consideración habrá de realizarse alertando acerca de dos riesgos que la propia escuela ha asumido en su discurso; un discurso de tono más apocalíptico que ve en la presencia de la cultura digital una amenaza efectiva para la cultura escrita y, en especial, para lo que se suele denominar "el hábito de la lectura", esto dicho en palabras propias del discurso cotidiano escolar y que, en algunos casos, es también asumido en el discurso de las políticas públicas; el segundo sentido posible también asumido por el discurso de la escuela es el de la celebración acrítica de la presencia de la cultura digital con un valor de puente intergeneracional que daría respuesta de actualización al supuesto envejecimiento de la cultura escolar y a las demandas de unas dinámicas "más entretenidas" en el trabajo cotidiano en las aulas.

Si consideramos la primera de las posiciones, la que hace hincapié en el déficit, habremos de comprenderla como subsidiaria de cierta tradición -que aún no ha sido suficientemente estudiada- sobre el posicionamiento que históricamente ha tenido la escuela frente a lo que recurrentemente ha leído en clave amenazante, a saber 
y cada uno en su tiempo, el cine, la ilustración, la fotonovela, la historieta, la televisión y finalmente, la cultura digital, es decir, fundamentalmente los objetos culturales que vienen asociados a lo visual (Bombini, 2006). Por otro lado, la posición centrada en las dificultades de los estudiantes en su relación con la cultura escrita forma parte de una construcción discursiva registrable históricamente que atraviesa los discursos didácticos y pedagógicos desde la propia fundación de la escuela. Desde allí, a lo largo de todo el siglo XX y hasta hoy podemos leer una trama de discursos que hacen hincapié en el "escaso o ausente hábito de la lectura", en la "falta de competencias o de habilidades para la lectura y la escritura", en la "dificultad para comprender los textos", e incluso se llega más contemporáneamente al señalamiento de ciertas patologías del lenguaje no detectadas en el ámbito de la escuela (dislexias, problemas de atención) que serían la causa de los déficits lingüísticos evaluados.

La segunda de las posiciones naturaliza y celebra el concepto de "nativo digital" y plantea una suerte de brecha intergeneracional: de un lado los estudiantes nativos digitales altamente predispuestos y con saberes prácticos experienciales que los habilitan para el manejo de los dispositivos electrónicos disponibles ("pueden abrir cinco pantallas a la vez") y del otro lado los docentes anquilosados en la defensa de representaciones y prácticas sobre la cultura escrita impresa y poco o nada diestros y, en algún sentido, desinteresados por el conocimiento y uso de las nuevas tecnologías y, acaso, por añadidura, detentadores de la concepción deficitaria de los estudiantes en su relación con la cultura escrita que hallaría precisamente su explicación en esa familiaridad con ese nuevo "mundo de la imagen" que por fin es el campo de la cultura digital. Al respecto observa de manera crítica Inés Dussel (Duseel, 2012, p. 185) el hecho de que "se ha instalado como sentido común una supuesta riqueza y variedad de las prácticas culturales de los jóvenes con los nuevos medios digitales" y, a la vez, se incurre -subraya Dussel- en una generalización acerca de la experiencia adolescente pero también acerca del mundo adulto al que se lo considera excluido de esa experiencia con dispositivos tecnológicos.

Hechas estas consideraciones cabría revisar aspectos referidos a desarrollos específicos observables en instancias de enseñanza o de formación en las que haya sido posible poner en juego otros puntos de partida e hipótesis de trabajo respecto de la relación entre prácticas de lectura y escritura y apropiaciones pedagógicodidácticas de la cultura digital.

En principio, podemos afirmar que el desarrollo de la cultura digital y todas las preguntas que suscita en el campo escolar la presencia de las diversas tecnologías disponibles en la vida cotidiana de niños y adolescentes parece poner en jaque, una vez más y por renovados motivos, a la propia cultura escolar.

Frente a esta tensión y a este desafío se ensayan diversas respuestas acerca de los modos en que la escuela podría superar lo que serían sus propias limitaciones; algunas de estas respuestas postulan la necesidad de actualizar los contenidos curriculares partiendo de un diagnóstico, acaso intuitivo, de que el mejor aprovechamiento, la más óptima inserción de las llamadas "nuevas tecnologías" tendría que ir necesariamente asociada a un proceso de cambio curricular frente a contenidos que se consideran "desactualizados" y que estarían conspirando contra la posibilidad de que las renovadas tecnologías desembarquen en la escuela con todas sus potencialidades.

Esta hipótesis es sin duda insuficiente para explicar la complejidad del cambio que supone el desarrollo de la cultura digital en términos de los modos en que se organiza, se produce y se trasmite el conocimiento en la escuela. Se trata de otros modos de "decir el conocimiento" y por ende de vincularnos con él. En principio se 
trata de no asumir para el uso de las tecnologías de lo digital una mirada restrictiva que reduzca a los materiales (sonoros, visuales, audiovisuales) que se ponen a disposición por estos medios, a meros "recursos" (como suele mencionárselos) ilustrativos o ejemplificadores respecto de unos textos lingüísticos que seguirían ocupando un lugar central y jerarquizado por sobre los otros medios no lingüísticos. La idea de que las imágenes cumplan la función de meros paratextos visuales de un texto escrito parte de una consideración subsidiaria de todo lo que no es el texto escrito, objeto de referencia de la cultura letrada tradicional. Se trata, pues, de salir de cierto logocentrismo que caracteriza a la tradición de las prácticas de enseñanza.

En este sentido, y para refutar la hipótesis más común que atribuye una versión menos rica del aprovechamiento de las tecnologías a la desactualización de los contenidos curriculares, sostenemos que el desafío que promueven estas tecnologías se podría entender como un desafío, un envite, a la que podríamos llamar "imaginación didáctica”. Nuevos modos de relacionarse con el conocimiento, nuevos modos de "decir" el conocimiento, estarán propiciando nuevos modos del hacer didáctico en el aula y en la biblioteca escolar que habrán de resolverse en varios sentidos. Por un lado, en términos de la organización de la tarea cotidiana y de la nueva lógica que supone la presencia de dispositivos electrónicos en el aula. Por otro lado, en términos de la convivencia de lenguajes, de objetos culturales diversos, que nos "llegan" a través de la pantalla y también de los dispositivos de reproducción de sonido que forman parte de una computadora, sea ésta de mesa, notebook, netbook, o cualquier otro dispositivo electrónico que se halle disponible en el aula. Con o sin conectividad disponible (lo marcará una diferencia no poco relevante), la escena es ahora la de un aula en la que los alumnos en lugar de una carpeta o cuaderno de apuntes y un bolígrafo, y acaso algún libro, tienen una netbook, otorgada en propiedad definitiva o como una posesión momentánea gracias a algún programa educativo que haya buscado la superación de la brecha digital facilitando en acceso a "las máquinas". Aún en la disposición del aula tradicional (escritorio y pizarrón al frente y filas de pupitres o mesas y sillas mirando a ese frente), cada alumno con un dispositivo digital a su alcance, el docente al frente acaso también con su propia máquina, la clase se sostendrá como siempre en la mediación oral del docente y en la participación oral de los estudiantes, pero los modos en que los éstos se irán poniendo en contacto con la lectura rebasará el modo de hacerlo como cuando lo que había ahí eran solo carpetas para apuntes y ocasionalmente un libro. Si se tratara de reconocer en una imagen a un presidente de mediados del siglo XX seguramente no solo se encontrarán imágenes fijas, fotografías de momentos relevantes del ejercicio de su mandato sino también grabaciones de entrevistas radiales o material audiovisual proveniente de algún archivo fílmico histórico o un fragmento de un documental o de un film de carácter más ficcional, de tema histórico. Además se mostrarán disponibles diferentes fuentes escritas: desde el correspondiente artículo de elaboración colaborativa de Wikipedia sobre ese presidente, un pdf con un capítulo de un libro específico referido al tema, artículos divulgativos y académicos, material periodístico (textos con o sin imágenes) de la época proveniente del repositorio digital de un archivo oficial o del periódico correspondiente y una muestra de iconografía alojada en la página oficial de museo histórico. Si se tratara de saber más sobre Beethoven bastaría con poner las palabras "Beethoven", "concierto", "piano", "quinto" para estar participando de una audición en la que podremos comparar no solo la interpretación orquestal de la Orquesta Filarmónica de Berlín con la de la Orquesta de Saint-Martín-in-the-field y los estilos de sus respectivos directores, sean estos el alemán Herbert Von Karajan o el venezolano Gustavo Dudamel, sino también las versiones de los pianistas Friedrich Goulda, Daniel Barenboim o Marta Argerich. De algunos registros tendremos solamente la grabación sonora y de otros una versión audiovisual en vivo donde, por ejemplo, podremos apreciar la magnitud de la sala de la Orquesta Filarmónica de Berlín o la arquitectura del Teatro Colón de Buenos Aires y observar además con algún detenimiento las actitudes del público en la recepción de la obra. 
No discutiremos aquí a qué tipo de curriculum de historia pertenece la primera de las búsquedas, o en qué tipo de saber en el campo de la didáctica de la música se incluiría el trabajo de cotejar interpretaciones de una misma obra musical; no tiene sentido preguntarse si se trata de un curriculum actualizado y pretendidamente adecuado a los intereses de los estudiantes o si se trata de una propuesta de enseñanza con algún dejo de antiguo enciclopedismo escolar. Esta consideración importa menos que el hecho de destacar la inmediatez y la diversidad del acceso a variados materiales en variados formatos en el espacio de la web y los desafíos didácticos que esta disponibilidad en el aula o en la biblioteca escolar estaría promoviendo.

En este sentido, el profesor Juan Daniel Ramírez y su equipo (Ramírez, 2012) de la Universidad Pablo de Olavide de Sevilla (España) ha venido trabajando con las posibilidades que las nuevas tecnologías ofrecen para la accesibilidad de aquellas fuentes que son la base de un proyecto de educación humanista. Ramírez destaca la incorporación de las TIC a la vida cotidiana y, más lentamente, a los sistemas educativos y puntualiza cuáles son las direcciones en las que se despliega esta inserción:

1. Acceso a las más diversas fuentes de información que hace posible la generación de un conocimiento multimodal sobre cualquier tópico estudiado (combinación de texto, imagen, música, video, etc.)

2. Superación de las barreras espaciales y temporales que puedan existir entre el aprendiz y la fuente de conocimiento.

3. Transformación de los usuarios que interactúan en red desde la creación de la web social (web 2.0.) cada uno de los cuales es a la vez receptor y generador de información y, en ocasiones, autor de conocimientos que pone al servicio de los demás participantes de las redes sociales.

El caso que toma Ramírez y su equipo es el de la web Art Project, una creación de la empresa google que reúne obras pictóricas fotografiadas y cedidas por diversos museos del mundo, y propone observar allí una selección de obras pictóricas de la Escuela Flamenca tomada de la colección del Rijsmuseum de Amsterdam y sobre este caso plantea objeciones y ventajas del acceso a las obras de arte a través de la pantalla.

El ejemplo de Ramirez permite poner en cuestionamiento aquellas posiciones reduccionistas que atribuían a la desactualización del curriculum su desajuste con la apropiación productiva de las tecnologías. Al asumir el contenido cultural del humanismo, una de las piedras basales de la configuración del sub-sistema de la educación secundaria, Ramírez está poniendo por sobre la coyuntura de tal o cual prescripción curricular, el hecho de que la escuela es la institución dentro de la cual se garantizará la reproducción social de un legado cultural entre generaciones y es la vuelta al aula de ciertos bienes culturales (en principio del humanismo occidental) gracias al acceso que permiten las nuevas tecnologías lo que permitirá recuperar la posición legitimista de la escuela como garante del acceso a los bienes de cierto canon de la cultura y en una pluralidad de manifestaciones (Privat, 2001). Se trata de un posicionamiento acerca de lo que se entiende por conocimiento escolar que lo busca incluirlo en series culturales más amplias, que exceden el campo del curriculum prescripto y que encuentra en la disponibilidad de acceso que ofrecen las nuevas tecnologías una clave didáctica fundamental. 
Del trabajo de investigación de Ramírez rescatamos también el uso del concepto de multimodalidad que habrá de operar como un concepto bisagra, articulador, entre prácticas que venían considerándose de manera contrapuesta y divorciada: la lectura y la escritura (y sus saberes y prácticas asociadas) como cometido fundacional de la escuela y las nuevas tecnologías en principio más asociadas de manera excluyente al campo de la cultura de la imagen.

En esta línea interesa recuperar los planteos que hace Carey Jewitt en su artículo "Multimodalidad, 'lectura' y 'escritura' para el siglo XXI" (Jewitt, 2005) donde, evitando partir de una polarización entre viejas prácticas y nuevas prácticas, Jewitt acuña el concepto de "nuevas configuraciones multimodales" y se propone observar el modo en que impactan en la producción escrita y en la práctica de lectura de los estudiantes. Se trata de una presencia cada vez más fuerte de la imagen que tiende a desestabilizar y a descentrar el habitual predominio del código lingüístico en el territorio escolar. En línea con los que planteábamos más arriba, en relación con la posibilidad de evitar la polarización entre prácticas/objetos lingüísticos y prácticas/objetos multimodales Jewitt afirma que la lectura y la escritura asentadas en el campo del impreso siempre han sido y siguen siendo multimodales. En tanto texto puesto en página y en determinada tipografía, la escritura en su dimensión material forma también parte del proceso de construcción de significado. La puesta en libro (u otro tipo de publicación impresa) de los textos es en sí misma una operación de construcción en clave de lo multimodal: el tamaño de página y la superficie de impresión, las tipografías (familias, cuerpo), el uso de itálicas, negritas y subrayados no son elementos meramente decorativos y adquieren significado junto a eventuales imágenes (fotografías, ilustraciones, mapas, cuadros que permiten visualizar información, signos iconográficos, entre otros) que pueden ser parte de la tradición de una producción cultural como es el caso de la literatura infantil o de una determinada propuesta de edición como es el caso del género hoy conocido como "novela gráfica” (García, 2010).

La multimodalidad como parte de las posibilidades de comunicar el conocimiento en el campo escolar viene experimentando una suerte de reconocimiento tardío de lo que históricamente ha estado invisibilizado y desestimado de las consideraciones de la cultura escolar; de hecho podríamos sumar el ejemplo de la tradicional lámina escolar colgada con chinches en bastidores en las paredes del aula y que permitía visualizar el proceso de fotosíntesis o el día de la instauración del primer gobierno patrio el 25 de mayo de 1810, poniendo a disposición un conocimiento fundamentalmente visual (podemos reconocer el ciclo del agua o el rostro de Cornelio Saavedra) con alguna apoyatura lingüística, que daba pie a tareas que se volcaban en el cuaderno de tareas. De estos usos de lo multimodal, de un cruce entre imágenes y textos se ha venido nutriendo la escuela y al respecto hay trabajos que precisamente han avanzado en el reconocimiento en la historia de la enseñanza de dispositivos visuales usados en las aulas a lo largo de décadas (Feldman, 2004).

En este sentido es posible sostener que la letra en pantalla que supone la presencia de nuevas configuraciones a las que Jewitt caracteriza como "ensambles multimodales complejos de sonido, movimiento animado y otros modos de representación y comunicación" (Jewitt, 2005) (siendo la escritura un modo entre otros de los que participan de ese ensamblaje), se producirá sobre una tradición hasta ahora poco reconocida que es la de la importancia educativa de la imagen. Podemos afimar que históricamente escritura e imagen han cooperado en los procesos de construcción de significado y de transmisión del conocimiento escolar. En línea con el reconocimiento de esta tradición histórica de la enseñanza podríamos decir que la lectura es entonces, por definición, una práctica multimodal pues no leemos sino en caracteres diseñados y en ocasiones acompañados de imágenes que refuerzan los significados. No leemos textos sino textos editados y diseñados en formatos de papel más o menos estandarizados y en este sentido, libros de texto, diccionarios y enciclopedias escolares 
reconocen una tradición editorial en la que edición, diseño e imágenes conforman un ensamblado histórico que acaso se haya vuelto más visible y relevante cultural y pedagógicamente a partir de los novedosos y más complejos ensamblados que propone la cultura digital. No hay duda de que el reconocimiento del carácter multimodal de los textos, tanto impresos como digitales, desafía a una revisión de las concepciones de la lectura y de la comprensión lectora, sean éstas más o menos teóricas o más o menos intuitivas, sean de carácter cognitivo o sociocultural. Por ejemplo, sostiene Jewitt que el territorio de lo multimodal se habrán de leer y escribir con mayor facilidad que en el ámbito de lo impreso, las narrativas no lineales.

De este modo podríamos decir que leer y escribir en la multimodalidad supone que los sujetos leen y escriben en interfaces complejas, donde letras, ilustraciones, fotos, imágenes en movimiento, sonidos y símbolos se articulan de manera interactiva y que asumido esto no hay modo de soslayar el hecho de que estas transformaciones tendrán consecuencias para el trabajo en el aula.

Asimismo, la biblioteca escolar, esa otra aula de la escuela nutrida de materiales para la garantizar el acceso a la bibliodiversidad, también será afectada en su lógica cotidiana en interfaces de trabajo compartido donde las micropolíticas del conocimiento escolar muestran sus aspectos más ricos respecto del aprovechamiento rico de los materiales librarios y no librarios que se circulan por la biblioteca.

De este modo, manipular en el ámbito de la biblioteca escolar tanto los materiales impresos, como los incluidos en las llamadas mediatecas, a la vez que se manipulan y se articulan desde la red virtual diversidad de otras fuentes de información ratifica la idea de la lectura y la escritura en la multimodalidad.

\section{Reflexiones finales}

Si volvemos a la pregunta inicial referida al mejor aprovechamiento didáctico de la cultura digital y si queremos indagar acerca de cuáles serían las mejores condiciones para su inserción en la práctica escolar cotidiana y, por fin, en la cultura escolar, entendemos que las nuevas tecnologías plantean un interrogante a los modos de hacer, a los modos de leer, de escribir y, por fin, de enseñar y de aprender. En ese sentido, los desafíos más interesantes serán aquellos que se pongan en juego en el espacio del aula y de la biblioteca. Se trata de desarrollos que no se producen desde las "máquinas" hacia las aulas, en el sentido de la formulación de consignas o secuencias didácticas a aplicar o del confiado desarrollo de "juegos" como antídoto a una escuela a la que se ha venido tildando de "aburrida" (Dussel, 2012), sino que los desarrollos de nuevas propuestas para el uso de las tecnologías en la escuela se darán en el formato y con los protocolos propios de prácticas de investigación didáctica en terreno en las que habrán de participar activamente los docentes a cargo de aulas, pues es solo en la implementación en la escena de aula escolar donde será posible avanzar en propuestas que garanticen una genuina apropiación de parte de los docentes no solo en cuanto a los aspectos técnicos en el manejo de las tecnologías sino también en la construcción de las propuestas didácticas y las nuevas configuraciones de prácticas que el aula y la bibliotecas habitadas por computadoras, tablets, celulares entre otros dispositivos habrá de propiciar.

\section{Referencias bibliográficas}

Bombini, G. (2004). Los arrabales de la literatura. La historia de la enseñanza literaria en la escuela secundaria argentina (1860-1960). Buenos Aires: Miño y Dávila y Facultad de Filosofía y Letras. UBA. 
Bombini, G. (2006). "Géneros difíciles en la escuela" en Bombini, G. (2015). Textos retocados. Lengua, literatura y enseñanza. Buenos Aires: El hacedor. p. 121-127.

de Certeau, M. (1980). "Leer: una cacerìa furtiva”. En de Certeau, M. La invención de lo cotidiano. I Artes de hacer. Mèxico: Universidad Iberoamericana. 1996.

Dussel, I. (2012). "Más allá del mito de los "nativos digitales. Jóvenes, escuela y saberes en la cultura digital". En Southwell, M. (2012) Entre generaciones. Exploraciones sobre educación, cultura e instituciones, pp. 183-213. Rosario: Flacso-Homo Sapiens.

Feldman, D. (2004). “Imágenes en la historia de la enseñanza: la lámina escolar”. Educ.Soc, vol. 25, № 86, abril pp. 75-101.

García, S. (2010). La novela gráfica. Bilbao: Astiberri Ediciones.

Jewitt, C. ([2005] 2016). "Multimodalidad, lectura y escritura para el siglo XXI". Lulú Coquette. Revista de Didáctica de la Lengua y la Literatura, № 7, pp. 23-45, 2016.

Piccini, M. (1993). "Lectura y escuela: entre las memorias tradicional y las memorias electrónicas”. En García Canclini, N. El consumo cultural en México. México: Consejo Nacional para la Cultura y las Artes.

Privat, J. ([1995] 2001). "Socio-lógicas de las didácticas de la lectura”. Lulú Coquette. Revista de Didáctica de la Lengua y la Literatura, $\mathrm{N}^{\circ} 1$, sept., pp. 47-63.

Ramírez, J. (2011). “Humanismos, arte y educación”. Lulú Coquette. Revista de Didáctica de la Lengua y la Literatura, $N^{\circ} 6$, pp. 12-27.

Abstract: Faced with certain apocalyptic positions from the school environment that predict the decline of the printed book against the presence of digital culture, the concept of multimodality (Jewitt, 2005) and the commitment to a didactic construction in the field of reading and writing developed from that concept, propose productive horizons in the territory of the classroom and the school library.

Key words: Reading - Writing - Multimodality - Didactics.

Resumo: Frente a certas posições apocalípticas provenientes do ambiente escolar que prevêem o declínio da leitura do livro impresso em frente à presença da cultura digital, o conceito de multimodalidade (Jewitt, 2005) eo compromisso com uma construção didática no campo da leitura e da escrita desenvolvidos a partir desse conceito, eles propõem horizontes produtivos no território da sala de aula e na biblioteca da escola.

Palavras chave: leitura - escrita - multimodalidade - didática.

[Las traducciones de los abstracts al inglés y portugués fueron supervisadas por el autor de cada artículo] 
Didáctica de la lectura y la escritura y multimodalidad fue publicado de la página 71 a página79 en Cuadernos del Centro de Estudios de Diseño y Comunicación №72 